\title{
Handhaving van privaatrecht door toezichthouders
}

\author{
Bespreking van het proefschrift van mr. C.A. Hage
}

\author{
Mr. L.F. Wiggers-Rus $t^{*}$
}

\begin{abstract}
1 Inleiding
Het te recenseren boek ${ }^{1}$ is op 13 december 2017 door Hage als proefschrift verdedigd aan de Universiteit Leiden. Zijn onderzoek heeft een heldere opzet. In verband met de vraagstelling en afbakening ervan omschrijft Hage zijn onderzoek als deels descriptief en deels normatief van aard. ${ }^{2}$ Ervan uitgaande dat privaatrechtelijk geaarde regels in toenemende mate bestuursrechtelijk worden gehandhaafd, onderzoekt Hage allereerst 'de descriptieve vraag' hoe bestuursrechtelijke toezichthouders desbetreffende regels toepassen. Daarbij komen aan de orde kwesties als: welke regels van het privaatrecht worden gehandhaafd, waarom is door de wetgever gekozen voor bestuursrechtelijke handhaving, en welke bestuursrechtelijke instrumenten worden hiervoor gebruikt? Hage concentreert zich daarbij vooral op het contractenrecht. Vanuit het antwoord op de genoemde vraag stelt hij vervolgens 'de normatieve vraag' aan de orde in hoeverre privaatrechtelijk geaarde regels zich eigenlijk lenen voor handhaving met bestuursrechtelijke middelen. Aan de hand van een analyse van besluiten van toezichthouders (en opvolgende rechtspraak), nader geproblematiseerd vanuit privaatrechtelijk oogpunt, gaat hij na of de achtergrond en visie van toezichthouders (niet) strijdig zijn met het privaatrecht, en waarom het bestuursrecht meer geschikt zou zijn dan privaatrechtelijke handhaving om de doelstellingen van een goede marktwerking en consumentenbescherming te bewerkstelligen. Onderzoeksgebieden zijn het telecommunicatierecht, het consumentenrecht en het financiële recht, gegeven de verschillende kenmerken van de betrokken markten en de daarmee samenhangende verschillen in toezicht.
\end{abstract}

Het door Hage behandelde onderwerp is uiterst actueel. Zijn proefschrift bevat een intensief onderzoek naar de wisselwerking tussen bestuursrecht en privaatrecht op de onderzoeksgebieden. Het daarbij gegeven inzicht in de jurisprudentiële ontwikkeling van het toezichtrecht is voor de praktijk van groot belang. In de volgende paragrafen zal dit proefschrift worden

\footnotetext{
Mr. L.F. Wiggers-Rust is raadsheer in het gerechtshof Arnhem-Leeuwarden, locatie Arnhem, en raadsheer-plaatsvervanger in het College van Beroep voor het bedrijfsleven $(\mathrm{CBb})$.

1. C.A. Hage, Handhaving van privaatrecht door toezichthouders (Recht en Praktijk, nr. CA17), Deventer: Wolters Kluwer 2017.

2. Hage 2017, par. 1.5.
}

besproken aan de hand van de volgende thema's: in paragraaf 2 de achtergrond voor de instelling van toezichthouders bij de handhaving van privaatrecht, in paragraaf 3 de wijze waarop dit toezicht in de verschillende, hiervoor al vermelde onderzoeksgebieden wordt gepraktiseerd en de problemen die zich daarbij voordoen, in paragraaf 4 de door Hage voorgestelde denkrichting ten behoeve van het vinden van oplossingen voor de geschetste problematiek, en in paragraaf 5 enkele concluderende opmerkingen.

\section{Achtergrond handhaving privaatrecht door toezichthouders}

Voor een goed begrip van de vraagstelling waarop zijn dissertatie ziet, geeft Hage (in hoofdstuk 2) eerst een schets van de ontwikkeling die zich vanuit het internationale verdragenrecht en het Europese supranationale recht heeft voorgedaan in de verhouding tussen de (oorspronkelijk) onderscheiden rechtsgebieden: het privaatrecht en het publiekrecht. Als kern van bedoeld onderscheid vermeldt hij dat het private gaat over het in vrijheid nastreven van het eigen geluk of belang, terwijl het publieke betrekking heeft op het gemeenschappelijke geluk of welvaart'. ${ }^{3}$ Hage bevestigt dat de grens tussen privaat- en publiekrecht niet eenvoudig is te trekken en dat met de toenemend sturende Europese regelgeving de verwevenheid van privaatrecht en publiekrecht groter is geworden. ${ }^{4} \mathrm{Hij}$ geeft tevens een schets van de handhavingsmogelijkheden die het privaatrecht en het publiekrecht bieden. Hij stelt daarbij voorop dat het privaatrecht vooral reparatoire sancties kent. Dat is in zoverre juist dat deze in antal, zoals ook door Hage beschreven, de boventoon voeren. Terecht noemt hij evenwel ook de in het privaatrecht frequent toegepaste gebods- en verbodsactie met preventief karakter en de collectieve actie (art. 3:305a Burgerlijk Wetboek (BW)), waarvan een preventieve werking kan uitgaan. De door Hage gelegde nadruk op de grote preventieve werking die uitgaat van art. 5:7 Algemene wet bestuursrecht (Awb), dat het bestuursorgaan de mogelijkheid biedt de - in art. 5:21 Awb als herstelsanctie gedefinieerde - last onder dwangsom al op te leggen op het moment dat

3. Hage 2017, p. 22

4. Hage 2017, par. 2.4; zie hierover ook L.F. Wiggers-Rust, Roeien tegen de stroom in?, NJB 2013/1999, p. 1374 e.v. 
het gevaar voor de overtreding klaarblijkelijk dreigt, ${ }^{5}$ zie ik niet nader onderbouwd wat betreft de omvang van het gebruik van die bevoegdheid (in kwantitatieve zin derhalve). Ook het privaatrecht kent de oplegging van dwangsommen ter voorkoming van dreigende overtredingen. Hage noemt evenwel tevens de bestuurlijke boete, die, zo leidt hij af uit de literatuur, onder meer door de afschrikwekkende werking ervan wordt gezien als efficiënt en effectief (in preventieve zin). ${ }^{6}$ Deze ontbreekt in het privaatrecht inderdaad. ${ }^{7}$

Hage licht toe dat het mededingingsrecht niet altijd toereikend is om misstanden op de markt te voorkomen. De Europese wetgever zet het contractenrecht dan ook mede in om marktpartijen (zonder dominante marktpositie), die er bijvoorbeeld oneerlijke handelspraktijken op na houden of consumenten onvoldoende informeren, aan te pakken. ${ }^{8}$ Het privaatrecht is daarop van oorsprong echter niet gericht. De Europese wetgever heeft dit ook ingezien en probeert privaatrechtelijke handhavingstekorten daarom met behulp van bestuursrechtelijke handhavingsmiddelen van publiekrechtelijke toezichthouders te beperken, aldus Hage. In dit kader wordt wel gesproken van 'regulatory private law'. Het bevorderen van de mededinging en het versterken van de positie van consumenten zijn de voornaamste redenen van het publieke toezicht.' Ook de toezichthouders kennen evenwel, aldus nog steeds Hage, weer hun problemen. Gedacht kan worden aan onder meer de (on)afhankelijkheid van politiek en marktpartijen, het legaliteitsbeginsel en open normen, de prioritering door toezichthouders en hun discretionaire bevoegdheid. ${ }^{10}$ Met name de laatstgenoemde twee 'problemen' relativeren nog het voordeel van (de mogelijkheid tot spontane) handhaving door toezichthouders boven de - door personen geïnitieerde - handhaving door de (bestuurs- en burgerlijke) rechter. ${ }^{11}$

\section{De toezichthouder als handhaver van privaatrecht}

\subsection{Inleiding}

In de hoofdstukken $3 \mathrm{t} / \mathrm{m} 5$ komt bij de verschillende toezichthouders (de ACM als handhaver van privaatrecht in het telecommunicatierecht, de ACM als handhaver van privaatrecht in het consumentenrecht en de AFM als handhaver van privaatrecht in het financiële recht) aan de orde de vraag 'op welke wijze getracht is de handhavingstekorten van het privaatrecht met behulp van bestuursrechtelijke middelen te ver-

5. Hage 2017, p. 25.

6. Hage 2017 , p. 25-26 met noot 59 en p. 51 . Mogelijk bedoelt Hage op p. 26, par. 2.3.3, laatste zin, de bestuurlijke boete in plaats van de last onder dwangsom.

7. Zie hierover O.O. Cherednychenko, De publiek- en privaatrechtelijke handhaving van het Europese privaatrecht: de nieuwe realiteit voor contracteren, Contracteren 2014, afl. 3, par. 4, waarin ook de vraag aan de orde komt of het privaatrecht niet punitiever zou moeten worden.

8. Hage 2017, par. 2.5.

9. Hage 2017, p. 41.

10. Hage 2017, par. 2.7

11. Vgl. ook Hage 2017, par. 2.7.4 en 2.7.5. helpen'. ${ }^{12}$ Hage geeft in deze hoofdstukken een schat aan informatie over de desbetreffende jurisprudentiële ontwikkeling, wat als een belangrijke verdienste van zijn werk kan worden beschouwd. Deelvragen die aan bod komen, zijn de potentiële strijdigheid van de achtergrond en visie van toezichthouders met het civiele recht en de vraag waarom bestuursrechtelijke handhaving meer geschikt zou zijn dan privaatrechtelijke handhaving om de doelstellingen van goede marktwerking en consumentenbescherming te bewerkstelligen. ${ }^{13}$ Ter beantwoording van die vragen analyseert Hage besluiten van toezichthouders en (opvolgende) jurisprudentie. Van de verschillende toezichthouders zal ik hier (in par. 3.2), gezien het karakter van een recensie, (slechts) enige specifieke aandacht besteden aan de ACM als handhaver van het telecommunicatierecht. Die handhaving van privaatrecht is, zoals Hage ook opmerkt, vanwege de geschilbeslechtende functie die de ACM hier heeft, ${ }^{14}$ aan te merken als 'een bijzondere eend in de juridische bijt'. Voorts wordt in paragraaf 3.3 ingegaan op de door Hage gesignaleerde (nog moeizame) wisselwerking tussen bestuursrecht en privaatrecht in de verschillende sectoren.

\subsection{De telecommunicatiemarkt}

Als eerste komt in hoofdstuk 3 de telecommunicatiemarkt aan de orde.

Hage licht toe dat vanuit Europa de desbetreffende regulering is ingegeven door het bevorderen van de interne markt. Om dit doel te bereiken zijn toezicht en regelgeving nodig. De Kaderrichtlijn ${ }^{15}$ vormt de basis voor het Nieuw Regelgevend Kader. De Richtlijn legt de taken vast van de nationaal regelgevende instanties (NRI's). In Nederland is de ACM de aangewezen NRI. Een belangrijke taak van de NRI's ter bewerkstelliging van de doelstellingen van de Richtlijn is geschilbeslechting (zie met name hoofdstuk 4, art. 20 van de Richtlijn). De $\mathrm{ACM}$ is een orgaan van een rechtspersoon die is ingesteld krachtens publiekrecht en derhalve een bestuursorgaan in de zin van art. 1:1 sub a Awb. De geschilbeslechtende bevoegdheid van de ACM is (in de Telecommunicatiewet ( $\mathrm{Tw}$ ) van 2004) in één algemeen artikel neergelegd, namelijk art. 12.2 Tw, met uitzondering van interconnectie (art. 6.2 Tw) en geschillen met betrekking tot de aanleg en instandhouding van kabels. ${ }^{16}$ Art. 12.2 lid 1 Tw geeft de ACM de bevoegdheid 'regels te stellen indien partijen voldoende hebben onderhandeld maar niet tot overeenstemming zijn gekomen' (derhalve in de precontractuele fase). ${ }^{17}$ Indien dat wel het geval is en uit die overeenkomst tussen partijen voortvloeiende verbintenissen of de wijze waarop zij worden nagekomen in strijd zijn met hetgeen bij of krachtens de Tw is bepaald, is de ACM op grond van art. 12.2 lid $2 \mathrm{Tw}$ bevoegd om de overeenkomst aan te vullen of te wijzigen. De geschilbeslechting door de ACM

12. Hage 2017, p. 31, met verwijzing (in noot 94) naar par. 3.2, 4.2 en 5.2.

13. Hage 2017, p. 8 en 426.

14. Zie Hage 2017, par. 3.4.3.

15. Official Journal 2002, L 108/33.

16. Hage 2017, par. 3.4.3.1.

17. Vgl. CBb 25 april 2001, ECLI:NL:CBB:2001:AB1647, r.o. 6.7. 
volgens art. 12.2 Tw vindt plaats op aanvraag van een bij dat geschil betrokken partij (derhalve niet op eigen initiatief van de toezichthouder; zie in dit verband ook hiervoor par. 2 in fine). Het gaat hier om geschillen tussen civielrechtelijke entiteiten, die door de ACM bij besluit in de zin van art. 1:3 Awb worden beslist.

Uit de door Hage behandelde besluiten over de toepassing van de genoemde bepalingen uit de Tw blijkt, aldus Hage, een terughoudende opstelling van de ACM ten aanzien van haar geschilbeslechtende bevoegdheid. Het College van Beroep voor het bedrijfsleven $(\mathrm{CBb})$ heeft geoordeeld dat OPTA (thans ACM) slechts bevoegd is regels te stellen als sprake is van een art. 12.2 lid $1 \mathrm{Tw}$ situatie. ${ }^{18}$ In het geval van toepassing van art. 12.2 lid $2 \mathrm{Tw}$ heeft de ACM de bevoegdheid om de overeenkomst aan te vullen of te wijzigen:

'Het College begrijpt deze bepaling aldus, dat partijen die ertoe overgaan een overeenkomst te sluiten op basis van een ingevolge de Tw op hen rustende verplichting, daarmee de mogelijkheid prijsgeven om OPTA te vragen hun verschillen van inzicht daarover te beslechten. Daarop is echter een uitzondering, namelijk de situatie waarin geoordeeld moet worden dat de uit die overeenkomst voortvloeiende verbintenissen of de wijze waarop deze worden nagekomen in strijd zijn met het bij of krachtens de Tw bepaalde.'

Hage betreurt het beperkte karakter van de bevoegdheid van de ACM, althans haar interpretatie daarvan. Hij bepleit een bredere opvatting door de ACM, althans uitbreiding van haar bevoegdheid. ${ }^{19}$ Het is de vraag of Hage daarmee voldoende het belang van contractsvrijheid in aanmerking neemt, waarmee in de Tw zo duidelijk rekening is gehouden. Slechts in nauw omschreven gevallen heeft de ACM de bevoegdheid regels te stellen (art. 12.2 lid $1 \mathrm{Tw}$ ) dan wel de overeenkomst aan te vullen of te wijzigen (art. 12.2 lid $2 \mathrm{Tw}$ ).

In verband met art. 12.2 lid $1 \mathrm{Tw}$ is Hage met name bevreesd dat partijen in de precontractuele fase tussen de wal en het schip raken als er privaatrechtelijk geen mogelijkheden aanwezig worden geacht en de partij bij de ACM pas terechtkan als er voldoende is onderhandeld. ${ }^{20}$ Die vrees lijkt mij in zoverre niet gerechtvaardigd, dat de onderhavige geschillenregeling, zoals in (art. 20 lid 5 van) de Kaderrichtlijn uitdrukkelijk is bepaald, ${ }^{21}$ het recht van elk der partijen om bij de rechterlijke instanties een procedure in te leiden, onverlet laat. Dit stemt overeen met art. 112 Grondwet en art. 6 Europees Verdrag tot bescherming van de rechten van de mens en de fundamentele vrijheden (EVRM). Partijen hebben binnen de (beperkte) bevoegdheidskring van de ACM dus de keuze voor de ACM

18. CBb 12 januari 2009, ECLI:NL:CBB:2009:BH3302, AB 2009/112 m.nt. G. Cartigny, r.o. 6.4.1.

19. Zie Hage 2017, bijv. p. 112, 127, 164, 166-168 en 442.

20. Zie Hage 2017, hoofdstuk 3, p. 91, noot 187.

21. Zo ook Hage 2017, p. 76 dan wel de burgerlijke rechter. Ik wijs in dit verband ook op de uitspraak van de Hoge Raad van 17 september 1982, ECLI:NL:HR:1982:AG4439, AB 1982/573, inzake Zegwaard/Knijnenburg, waarin de Hoge Raad (in r.o. 3.1) als volgt oordeelde:

'Middel I miskent dat aan een - niet tegen de overheid gerichte - vordering voor de gewone rechter, al of niet in kort geding, waarbij de eisende partij een rechterlijk verbod vraagt van jegens haar onrechtmatige gedragingen van gedaagde, op zichzelf niet in de weg staat dat er, bij gebruikmaking van administratiefrechtelijke rechtsgangen, ook andere wegen bestaan, waarlangs bereikt zou kunnen worden dat gedaagde ten gevolge van maatregelen van de overheid zijn gewraakte gedragingen staakt. Middel I kan daarom niet tot cassatie leiden. ${ }^{22}$

Uiteraard zal de burgerlijke rechter in zijn beoordeling van de zaak de op partijen volgens de $\mathrm{Tw}$ rustende verplichtingen (hebben te) betrekken. De vrees van Hage dat de burgerlijke rechter in zaken die nog in (het begin van) het precontractuele stadium verkeren, de $T_{w}$ met onderhandelingsplicht niet in aanmerking zou nemen, maar in deze zaken de rechtspraak uit zaken als Plas-Valburg onverkort zou toepassen, ${ }^{23}$ heeft voor zover mij bekend geen precedent in de rechtspraak.

Indien echter een aanvraag van een bij het desbetreffende geschil betrokken partij tot geschilbeslechting bij de ACM zal zijn ingediend, en de zaak valt binnen haar bevoegdheidskring, dan ligt voor de hand dat de burgerlijke rechter de geschilbeslechting uit overwegingen van een goede taakverdeling en ter voorkoming van tegenstrijdige uitspraken aan de ACM overlaat, mede gegeven de mogelijkheid van beroep bij de bestuursrechter. De burgerlijke rechter heeft zich er dan uiteraard wel deugdelijk van te vergewissen of de beoordeling van het geschil inderdaad (volledig) binnen de bevoegdheidskring van de ACM valt, zodat de verschillende aspecten van de zaak ten volle aan bod zullen kunnen komen. De burgerlijke rechter zal voorts uitgaan van het bindend karakter van een onherroepelijke beslissing van de toezichthouder (waartegen bezwaar en vervolgens beroep bij de bestuursrechter heeft opengestaan). Een andere opvatting zou afbreuk doen aan het stelsel van bindende geschilbeslechting dat volgens de onderhavige regelgeving geldt. ${ }^{24}$

22. Zie in die zin ook L.F.M. Verhey \& N. Verheij, Handelingen NJV 2005-1, Deventer: Kluwer 2005, p. 160-161. Onzeker daarover is G. Cartigny blijkens zijn noot onder het hiervoor in noot 18 genoemde arrest van het $\mathrm{CBb}$ onder 5 .

23. Zie Hage 2017, bijv. par. 3.5.2.5, met verwijzing naar de MvT, waarin wordt vermeld dat bij een weigering tot onderhandelen door een van de partijen naast de bestuursrechtelijke ook de privaatrechtelijke weg openstaat, waarop het privaatrechtelijke jurisprudentiekader van afgebroken onderhandelingen van toepassing is (Kamerstukken II 2002/03, 28851, 3, p. 106).

24. Zie in die zin ook HR 26 juni 2015, ECLI:NL:HR:2015:1750, NJ 2016/275 m.nt. J.S. Kortmann. 
Voor de ACM en daarmee voor de bestuursrechter, die over de tussenkomst van de ACM oordeelt, is, zoals hiervoor al tot uitdrukking kwam, de vraag of een overeenkomst tot stand is gekomen bepalend voor de bevoegdheid van de ACM. Indien van een overeenkomst nog geen sprake is, is de ACM bevoegd regels te stellen, mits voldoende is onderhandeld (vgl. art. 12.2 lid $1 \mathrm{Tw}$ ). Is daarvan wel sprake, dan heeft de ACM de bevoegdheid om de overeenkomst aan te vullen of te wijzigen, ervan uitgaande dat de uit die overeenkomst tussen partijen voortvloeiende verbintenissen of de wijze waarop zij worden nagekomen in strijd zijn met hetgeen bij of krachtens de Tw is bepaald. Het $\mathrm{CBb}$ heeft op dit punt al diverse richtinggevende uitspraken gedaan, hetgeen de wisselwerking tussen de ACM en de burgerlijke rechter, en daarmee de geschillenbeslechting in deze zaken, ten goede kan en zal komen. Naarmate de jurisprudentie zich ontwikkelt, zal over de (beperkte, aanvullende) bevoegdheid van de ACM en de gevallen waarin zij een geschil kan beslechten, meer duidelijkheid ontstaan. Daaraan levert het rechtspraakoverzicht in het proefschrift van Hage zeker een bijdrage.

\subsection{De wisselwerking tussen bestuursrecht en privaatrecht blijkt voor verbetering vatbaar}

Met zijn overzicht van de jurisprudentie in de verschillende sectoren makt Hage heel duidelijk dat de praktijk nog in hoge mate met de verwevenheid van privaatrecht en publiekrecht worstelt. Hij geeft daarvan talloze voorbeelden, die hier uiteraard niet alle kunnen worden vermeld.

In hoofdstuk 3 over het telecommunicatierecht vormt een voorbeeld de beoordeling van de vraag of tussen partijen wilsovereenstemming bestaat: de toezichthouder kijkt daarvoor vooral of er een schriftelijke overeenkomst is; de burgerlijke rechter echter weegt ook de overige omstandigheden van het geval mee voor zijn desbetreffende beslissing. Met Hage ben ik van mening dat voor bedoelde vraag de privaatrechtelijke jurisprudentie ook door de toezichthouder tot uitgangspunt dient te worden genomen. ${ }^{25}$ Het gaat hier immers om een civielrechtelijke vraag. De ACM zal haar aanvullende, geschilbeslechtende taak slechts deugdelijk kunnen verrichten als zij haar rol in afstemming op de desbetreffende rechtspraak en literatuur vervult. Een dergelijke afstemming kan het meest vruchtbaar in onderlinge dialoog tussen (de beoefenaars van) het bestuursrecht en het privaatrecht plaatsvinden. ${ }^{26}$ Voor vorderingen die niet binnen haar bevoegdheidskring liggen, is voor een goede rechtsbedeling tijdige verwijzing door de ACM naar de burgerlijke rechter aan te bevelen. Dit geldt bijvoorbeeld ook voor terugvordering van te veel betaalde gelden. Duidelijkheid daarover zal een toegankelijke en voorspoedige geschilbeslechting overeenkomstig tevoren bestaande verwachtingen kunnen bevorderen.

25. Vgl. Hage 2017, bijv. par. 3.5.3.4, p. 104.

26. Zie hierover ook L.F. Wiggers-Rust, Interne rechtsvergelijking in de meergelaagde rechtsorde, NJB 2017/1645, p. 2148 e.v.
Ten aanzien van het consumentenrecht (hoofdstuk 4) acht Hage een vergelijking tussen de bestuursrechtelijke en de privaatrechtelijke handhaving van de in het BW opgenomen bepalingen omtrent de onrechtmatigheid van oneerlijke handelspraktijken (art. 6:193a e.v. BW) lastig, omdat er weinig privaatrechtelijke uitspraken zijn. Van die bepalingen maken, zo concludeert hij, ${ }^{27}$ nog weinig consumenten gebruik. Op dit rechtsgebied probeert de toezichthouder het gedrag van contractanten wel duidelijk te sturen met het opleggen van boetes. De informatieplichten en de handhavingsmiddelen voor consumenten komen Hage toegankelijker voor. Hij leidt dit af uit het (frequent en succesvol) beroep op art. 6:230m e.v. BW door consumenten zelf. ${ }^{28}$ Hage signaleert spanning tussen het opleggen van boetes wegens overtreding van open en vage normen en het legaliteitsbeginsel (art. 7 EVRM). Boetes van de ACM blijken in bezwaar en beroep zowel bij de precontractuele informatieplichten als bij de oneerlijke handelspraktijken ook nogal eens te worden gematigd. Hage trekt hieruit de voorzichtige conclusie dat de ACM open normen (te) onvriendelijk voor ondernemers uitlegt. ${ }^{29}$ Een probleem dat Hage in dit rechtsgebied verder signaleert, is het niet eenduidige karakter van de definitie van de 'gemiddelde consument' in het privaatrecht en bestuursrecht. ${ }^{30}$ Terwijl de burgerlijke rechter zich, overeenkomstig de jurisprudentie van het Hof van Justitie van de EU, lijkt te richten op de redelijk geïnformeerde, omzichtige en oplettende consument, lijkt de bestuursrechter de lat voor bedrijven volgens Hage hoger te leggen en sneller te oordelen dat de consument is misleid. Hage betreurt, zo begrijp ik, dat consumenten voor schadevergoeding aangewezen blijven op de civiele rechter. ${ }^{31}$

Ook in het financiële recht (hoofdstuk 5) staan het algemeen belang en de bescherming van de zwakkere partij in het publiekrechtelijk toezicht centraal, ingevolge aanzienlijke invloed van het EU-recht. Binnen het gedragsrecht zijn verschillende privaatrechtelijke regels omgezet in publiekrechtelijke regels. Een belangrijk voorbeeld vormt de zorgplicht van banken. Deze is vooral in de jurisprudentie van de burgerlijke rechter ontwikkeld ter bescherming van de belangen van de individuele contractspartij (art. 7:401 BW). In 2014 is in de Wet op het financieel toezicht (Wft) een nieuwe generieke zorgplicht ingevoerd (art. 4:24a Wft). ${ }^{32}$ Ook in het financiële recht speelt de spanning tussen de als open normen geformuleerde zorgplichten en de handhaving ervan met punitieve sancties (art. 7 EVRM). ${ }^{33}$ Hage schetst (opnieuw) helder de verschillende doelstellingen van het bestuursrecht en het privaatrecht. Het bestuursrecht streeft het algemeen belang na: zo moet de financiële instelling informeren, ongeacht of de consument al door een adviseur is geïnformeerd. In het pri-

27. Zie Hage 2017, par. 4.6, p. 276

28. Idem.

29. Hage 2017 , par. 4.6 , p. 277.

30. Zie Hage 2017 , par. 4.6, p. $278-279$.

31. Vgl. Hage 2017 , p. 282 in combinatie met zijn verdere uitwerking in hoofdstuk 6 (par. 6.4.4).

32. Vgl. Hage 2017, par. 5.1.3.

33. Zie Hage 2017, par. 5.7, p. 420 e.v. 
vaatrecht staat het individuele belang centraal: is de individuele consument, in het concrete geval, geïnformeerd? Hier werkt het verschil in achtergrond tussen bestuursrecht en privaatrecht door in de handhaving ervan. Ten gunste van het bewerkstelligen van goed werkende financiële markten wordt als het ware van de individuele omstandigheden van het geval geabstraheerd. De publiekrechtelijke en privaatrechtelijke zorgplicht kunnen dan ook niet zonder meer op één lijn worden gesteld. De beoordelingskaders verschillen. ${ }^{34}$

\section{Hoe nu verder?}

In hoofdstuk 6 komen de resultaten van de hiervoor in paragraaf 1 vermelde onderzoeksvragen aan bod en geeft Hage antwoord op gestelde vragen. In paragraaf 6.2 gaat hij in op de vraag waarom voor bestuursrechtelijke handhaving is gekozen, in paragraaf 6.3 op de door de toezichthouder in verband met privaatrechtelijk geaarde regels gebruikte bestuursrechtelijke handhavingsmiddelen. Hij formuleert in laatstgenoemde paragraaf specifieke kenmerken van handhaving door de toezichthouder bij (grootschalige) inbreuken. Voorbeelden zijn 'geabstraheerde handhaving', dat wil zeggen geabstraheerd van individuele omstandigheden, de spanning tussen de handhaving van open normen en art. 7 EVRM, de door de toezichthouder (ACM) gehanteerde en in het civiele recht afgewezen iustum pretium-gedachte en een (wat boetes betreft) (te) actieve toezichthouder. ${ }^{35}$ Voorts somt hij tekorten van bestuursrechtelijke handhaving op, zoals het niet geschikt zijn van de last onder dwangsom voor het ongedaan maken van sommige overtredingen, denk aan door een telecomaanbieder gevraagde te hoge tarieven; de betrokkene moet daarvoor de burgerlijke rechter benaderen. Daarnaast noemt Hage het niet meewegen door de toezichthouder van individuele omstandigheden, bijvoorbeeld van derden, en het niet voorzien in schadecompensatie bij het bestuursrechtelijke besluit. Hage ziet daarin argumenten voor een meer hybride vorm van handhaving, ${ }^{36}$ waaraan hij zijn slotparagraaf (par. 6.4) mede wijdt. Daarin vergelijkt hij het aansluiten van privaat- en publiekrecht op elkaar (complementariteit) met de zogenoemde hybride handhaving, waarin deze volledig in handen zou komen van een bestuursrechtelijke instantie. Daarmee zouden niet alleen de vaststelling en het sanctioneren van de overtreding, maar ook de afwikkeling van de met de overtreding samenhangende schadevergoedingsacties bij de bestuursrechtelijke instantie komen te liggen. Dit voorkomt, aldus Hage, een cumulatie van procedures en het gevaar van tegenstrijdige uitspraken. Hage schetst voorbeelden uit binnen- en vooral buitenland. ${ }^{37}$ In Nederland bestaan grensoverschrijdende oplossingen met name uit voorstellen en wetswijzigingen van coördinerende aard. ${ }^{38}$ Zoals de wetgever in de Nederlandse reactie op de mededeling van de Europese Commissie 'Naar een Europees

34. Vgl. voor een en ander Hage 2017, onder meer par. 5.7.

35. Hage 2017, par. 6.3.2 t/m 6.3.5

36. Hage 2017, par. 6.3.6.

37. Hage 2017, par. 6.4.4.1 en 6.4.4.2.

38. Hage 2017, par. 6.4.4.3 met verwijzing naar par. 6.4.3; met 'grens' wordt hier kennelijk gedoeld op de scheidslijn tussen privaatrecht en bestuursrecht. horizontaal kader voor collectief verhaal' opmerkte, zijn publiekrechtelijke toezichthouders niet gericht op schadevergoeding. ${ }^{39}$ Hage onderkent zelf naast voordelen ook nadelen van hybride handhaving, omdat coördinatie met het privaatrecht hoe dan ook nodig blijft en toezichthouders met beperkte middelen prioriteiten moeten stellen. ${ }^{40}$

\section{Conclusie}

Al met al heeft Hage een veelomvattend onderzoek gedaan naar de handhaving van (contractueel) privaatrecht door bestuursrechtelijke toezichthouders en de problemen in wisselwerking tussen bestuursrecht en privaatrecht die zich daarbij voordoen. Hij heeft zich in drie complexe sectoren verdiept en de zich daarin voordoende ontwikkelingen in de jurisprudentie weergegeven en geanalyseerd. Dat is een enorm werk geweest. Een dergelijk overzicht ontbrak tot op heden en kan ook een naslagwerk vormen. De gedachtegang van Hage is inzichtelijk, evenals zijn methode en bronnengebruik; een omvangrijk notenapparaat maakt verder onderzoek mogelijk. Het proefschrift van Hage kan baanbrekend worden genoemd, in die zin dat het vele handvatten biedt voor verder onderzoek van door Hage gesignaleerde problemen en de oplossing daarvan. Wie van het werk van Hage kennisneemt, zal er zonder meer van overtuigd zijn dat de verwevenheid van privaatrecht en publiekrecht de praktijk nog voor de nodige problemen stelt. Hage heeft de zwakke kanten van bestuursen privaatrechtelijke handhaving uiteengezet (ik plaatste daarbij hiervoor wel enkele kanttekeningen). Hij tendeert aan het slot van zijn onderzoek naar vormen van hybride handhaving. Juist ook op dat punt is verder debat interessant: zouden door samenwerking tussen bestuursrecht en privaatrecht in goede aansluiting op en wisselwerking met elkaar zwakheden van elk van beide niet kunnen worden opgeheven en de handhaving in haar geheel kunnen worden geoptimaliseerd? Voorgestaan wordt in dit verband, ook vanuit rechtseconomische zijde, wel een optimale mix van publiek- en privaatrechtelijke handhaving. ${ }^{41}$ Het lijkt mij goed daarbij voor het privaatrecht ook te kijken naar het conceptwetsvoorstel Experimentenwet rechtspleging, dat ruimte biedt om te experimenteren met eenvoudige procedures die partijen bij elkaar brengen en conflicten niet op de spits drijven. De wetgever en de rechtspraktijk moeten de grote veranderingen die zich in het recht voordoen naar mijn mening in dialoog tussen publiekrecht en privaatrecht 'te lijf gaan' ten behoeve van een nieuw effectief evenwicht, waarin ten gunste van algemene én individuele belangen een deugdelijk geïntegreerde aanpak van de handhaving in goede wisselwerking tot stand wordt gebracht. Het proefschrift van Hage biedt daarvoor voldoende aanknopingspunten!

39. Hage 2017, par. 6.4.4.3, p. 460-461.

40. Hage 2017, par. 6.4.4.5.

41. Zie over 'een optimale mix van publiek- en privaatrechtelijke handhaving' ook Cherednychenko 2014, par. 4. 